\title{
Ablation of capsaicin sensitive afferent nerves impairs defence but not rapid repair of rat gastric
} \section{mucosa}

\author{
M A Pabst, E Schöninkle, P Holzer
}

\begin{abstract}
Capsaicin sensitive afferent neurones have previously been reported to play a part in gastric mucosal protection. The aim of this study was to investigate whether these nociceptive neurones strengthen mucosal defence against injury or promote rapid repair of the damaged mucosa, or both. This hypothesis was examined in anaesthetised rats whose stomachs were perfused with ethanol (25 or $50 \%$ in saline, wt/wt) for 30 minutes. The gastric mucosa was inspected 0 and 180 minutes after ethanol had been given at the macroscopic, light, and scanning electron microscopic level. Rapid repair of the ethanol injured gastric mucosa (reduction of deep injury, partial re-epithelialisation of the denuded surface) took place in rats anaesthetised with phenobarbital, but not in those anaesthetised with urethane. Afferent nerve ablation as a result of treating rats with a neurotoxic dose of capsaicin before the experiment significantly aggravated ethanol induced damage as shown by an increase in the area and depth of mucosal erosions. Rapid repair of the injured mucosa, however, as seen in rats anaesthetised with phenobarbital 180 minutes after ethanol was given, was similar in capsaicin and vehicle pretreated animals. Ablation of capsaicin sensitive afferent neurones was verified by a depletion of calcitonin gene related peptide from the gastric corpus wall. These findings indicate that nociceptive neurones control mechanisms of defence against acute injury but are not required for rapid repair of injured mucosa.

(Gut 1993; 34: 897-903)
\end{abstract}

There is twofold evidence that capsaicin sensitive (nociceptive) afferent neurones affect gastric mucosal protection. Firstly, ablation of these neurones increases the susceptibility of the rat gastric mucosa to injurious factors such as hydrochloric acid, acetylsalicylic acid, and ethanol. ${ }^{1-6}$ Secondly, stimulation of capsaicin sensitive neurones in the stomach enhances the resistance of the gastric mucosa against experimentally imposed damage. ${ }^{17-11}$

The capacity of the gastric mucosa to protect itself from injury is determined by many factors, ${ }^{12}$ and aggravation of experimental injury as seen after sensory nerve ablation may result either from impairment of mucosal defence or retardation of rapid repair or both. Instrumental in the latter is the process of restitution, by which epithelial continuity is re-established by mucous cells emigrating from the gastric pits. ${ }^{13-16}$
Capsaicin sensitive afferent neurones may affect both defence and repair mechanisms in the gastric mucosa, because they are sensitive to a variety of noxious stimuli ${ }^{17}$ and have been reported to play both a defensive and trophic part in somatic tissues. ${ }^{18-22}$ The aim of this study, therefore, was to examine whether capsaicin induced ablation of afferent neurones would impede rapid repair of the ethanol damaged rat gastric mucosa.

\section{Methods}

\section{ANIMAL PREPARATION}

This study was approved by the Ministry of Science and Research of the Republic of Austria on the basis that all animal experiments were carried out under general anaesthesia. SpragueDawley rats, of either sex and 240-280 g body weight, were used. The animals were deprived of food for 20 hours before the experiments but allowed free access to water. The rats were anaesthetised either by a subcutaneous injection of urethane $(1.5 \mathrm{~g} / \mathrm{kg})$ or an intraperitoneal injection of sodium phenobarbital $(0 \cdot 23 \mathrm{~g} / \mathrm{kg})$. The body temperature of the animals was kept at $36-37^{\circ} \mathrm{C}$ by means of heating lamps. Saline $(0.9 \% \mathrm{NaCl}, \mathrm{wt} / \mathrm{wt})$ was continuously infused into a jugular vein at a rate of $1.5 \mathrm{ml} / \mathrm{h}$ to avoid dehydration. ${ }^{610}$ The stomach, exposed by a midline laparotomy, was prepared for continuous perfusion by an inflow cannula inserted through the oesophagus and an outflow cannula inserted through the pylorus. ${ }^{8-10}$ After flushing the stomachs with $50 \mathrm{ml}$ saline to remove any solid contents, a period of one hour was allowed for equilibration during which the stomach was continuously perfused with saline (room temperature) at a rate of $0.7-0.8 \mathrm{ml} / \mathrm{min}$. Thereafter, the stomach was perfused with ethanol (25 or $50 \%, \mathrm{wt} / \mathrm{wt}$ ) in saline to induce the formation of gastric erosions. For examination of mucosal injury, the stomachs were excised, opened along the greater curvature, pinned flat on a board, and processed for assessment of damage at the gross, light, and scanning electron microscopic level. ${ }^{8-10}$

\section{TREATMENT WITH CAPSAICIN}

Rats were pretreated subcutaneously with a total dose of $125 \mathrm{mg} / \mathrm{kg}$ capsaicin 14 days before the experiments. ${ }^{6710}$ This dose of capsaicin was given in four injections over two days (first day: $25 \mathrm{mg} / \mathrm{kg}$ in the morning and $25 \mathrm{mg} / \mathrm{kg}$ in the late afternoon, second day: $25 \mathrm{mg} / \mathrm{kg}$ in the morning and $50 \mathrm{mg} / \mathrm{kg}$ in the late afternoon). 

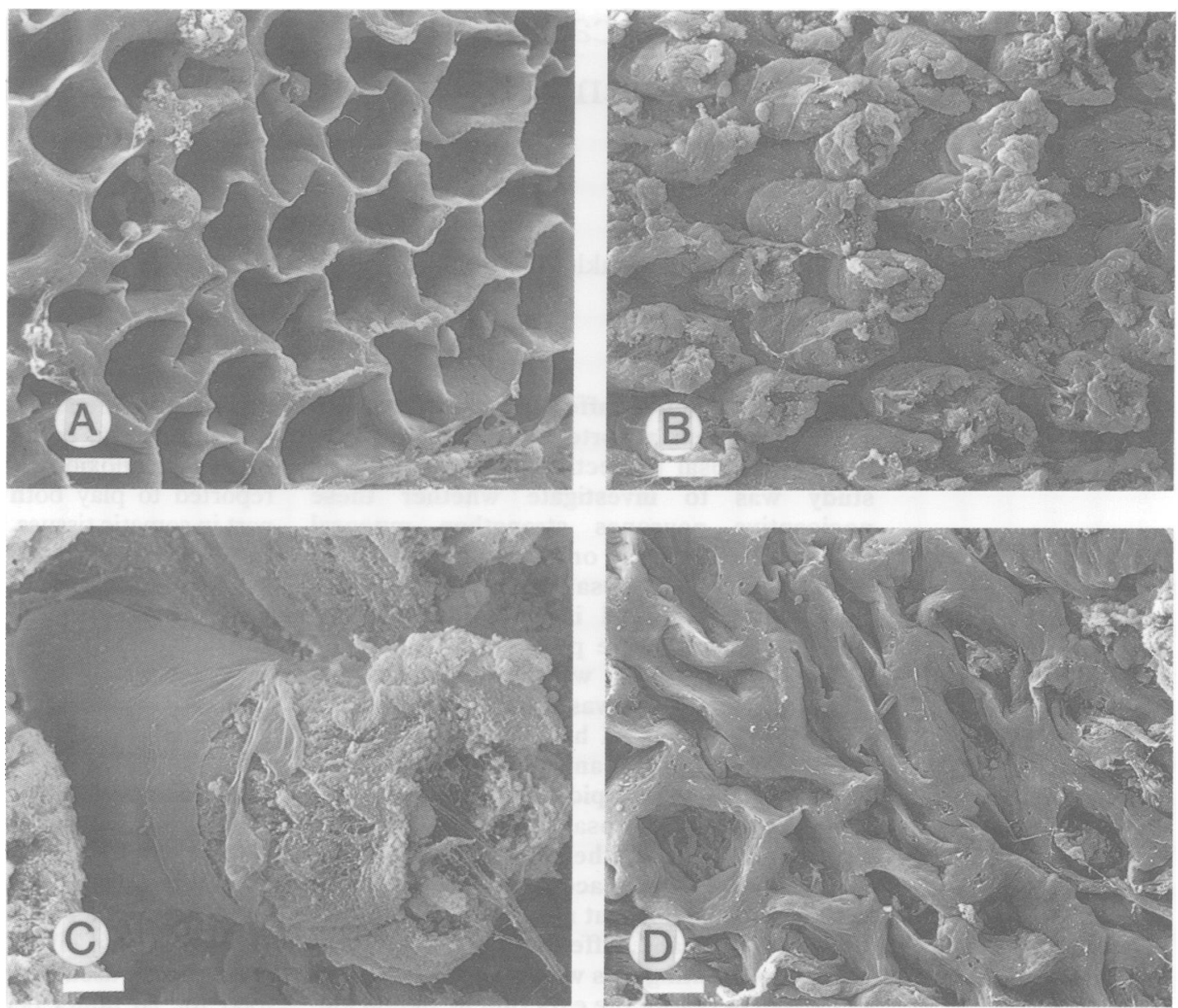

Figure 1: Scanning electron microscopic appearance of the gastric corpus mucosa taken after a 30 minute perfusion of the stomach of rats anaesthetised with urethane with $25 \%$ ethanol. The stomachs were processed for histological examination immediately after the ethanol perfusion $(A)$ or after 15 minutes $(B, C)$ and 180 minutes $(D)$ of perfusion with saline after ethanol. Calibration bars in $A, B$, and $D: 20 \mu \mathrm{m}$, in $C: 5 \mu \mathrm{m}$. The photomicrographs show complete ablation of the surface epithelium $(A)$ followed by expulsion of damaged gastric glands $(B, C)$, and swelling of the denuded lamina propria $(D)$.

The control rats received equal volumes of vehicle $(2+2+2+4 \mathrm{mg} / \mathrm{kg})$. All injections of capsaicin and its vehicle were given under ether anaesthesia. To counteract the respiratory impairment associated with the administration of capsaicin, the rats received an intraperitoneal

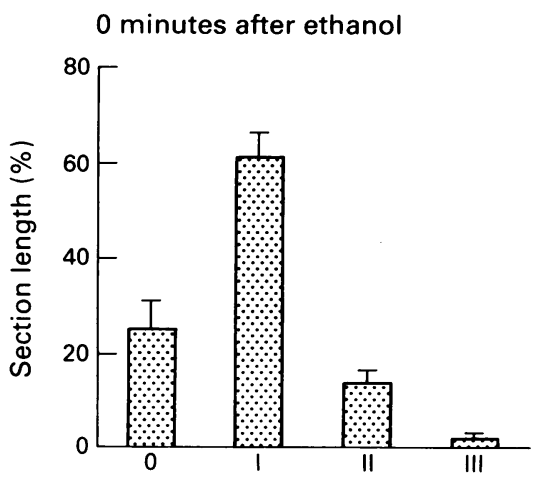

180 minutes after ethanol

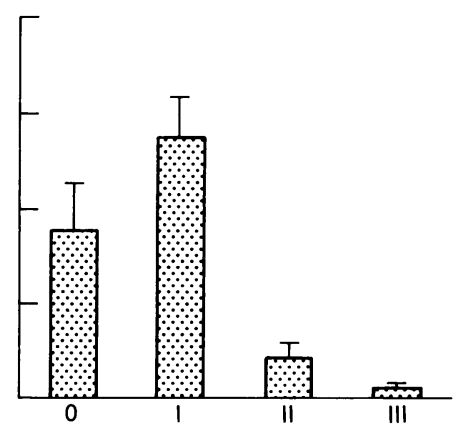

Injury grades

Figure 2: Histological injury in the gastric mucosa of rats anaesthetised with urethane assessed immediately after a 30 minute perfusion of the stomach with $25 \%$ ethanol ( 0 minutes after ethanol) and after 180 minutes of gastric perfusion with saline after ethanol (180 minutes after ethanol). Four grades of histological injury were recorded: 0 , no damage or damage involving only the surface epithelial cells; I, shallow damage involving up to $10 \%$ of the mucosal depth; II, medium damage involving up to $25 \%$ of the mucosal depth; and III, deep damage involving $>25 \%$ of the mucosal depth. The section length occupied by the respective injury grades was expressed as a percentage of the total section length. Mean (SEM), $n=8$. injection of atropine $(0 \cdot 2 \mathrm{mg} / \mathrm{kg})$, terbutaline $(0.2 \mathrm{mg} / \mathrm{kg})$ and aminophylline $(20 \mathrm{mg} / \mathrm{kg})$ before the first and third capsaicin or vehicle injection. ${ }^{4}$ The effectiveness of capsaicin pretreatment was assessed by determination of the calcitonin gene related peptide content of the gastric corpus wall, because in the rat stomach this peptide is almost exclusively contained in capsaicin sensitive afferent neurones. ${ }^{2324}$ Therefore, a biopsy specimen from macroscopically intact areas of the gastric corpus (full thickness, $100-200 \mathrm{mg}$ wet weight) was excised at the end of a 30 minute perfusion of the stomach with ethanol. The tissue samples were blotted on filter paper, frozen in liquid nitrogen, weighed, and homogenised in $2 \mathrm{ml}$ of acetic acid $(2 \mathrm{~N})$ by ultrasonication. The homogenates were centrifuged at $3000 \times g$ for 15 minutes. The pellet was resuspended in $1 \mathrm{ml}$ of acetic acid $(2 \mathrm{~N})$ and centrifuged again. The combined supernatants were freeze dried and dissolved in radioimmunoassay buffer, and their calcitonin gene related peptide content was assessed by a specific radioimmunoassay. ${ }^{25}$

EXAMINATION OF HISTOLOGICAL INJURY

Histological injury of the gastric mucosa was assessed by light and scanning electron micro- 
Control

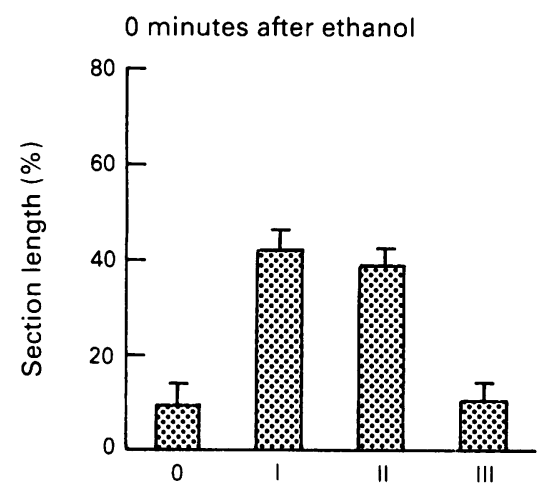

180 minutes after ethanol

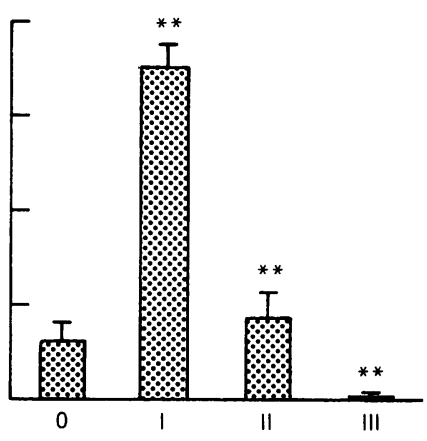

Capsaicin

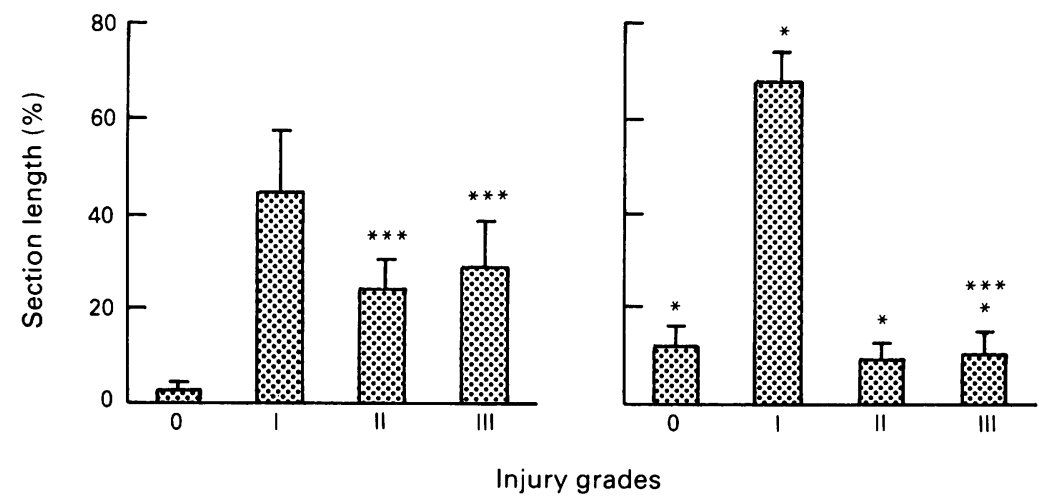

Figure 3: Histological injury in the gastric mucosa of rats anaesthetised with phenobarbital assessed immediately after a 30 minute perfusion of the stomach with $50 \%$ ethanol ( 0 minutes after ethanol) and after 180 minutes of gastric perfusion with saline after ethanol (180 minutes after ethanol). The injury grades were the same as in Figure 2. The graphs compare the injury scores in vehicle pretreated (control) and capsaicin pretreated (capsaicin) rats. Mean $(S E M)$ $n=8-9 .{ }^{\star} p<0.05,{ }^{\star}{ }^{\star} p<0.01 \mathrm{v}$ respective injury grades measured 0 minutes after ethanol; $\star \star \star p<0.05 \mathrm{v}$ respective injury grades measured in the control rats.

scopy. ${ }^{89}$ The excised stomachs were placed in fixative $(2 \cdot 5 \%$ glutaraldehyde, $2 \%$ paraformaldehyde in $0 \cdot 1 \mathrm{M}$ cacodylate buffer of $\mathrm{pH} 7 \cdot 2$ ). For scanning electron microscopy, the tissues were left in the fixative for three hours at room temperature. Thereafter, pieces of tissue were cut from the gastric corpus and processed for examination on a scanning electron microscope (DSM 950, Zeiss, Oberkochen, Germany).

For light microscopic examination, pieces of tissue from the gastric corpus were left in the fixative for three days at room temperature and, after dehydration in a graded series of ethanol, were embedded in Historesin (LKB, Bromma, Sweden). Four micrometer sections were cut and stained with a mixture of methylene blue azure II and basic fuchsin. ${ }^{89}$

Histological injury in the gastric mucosa of untreated rats anaesthetised with phenobarbital assessed immediately after a 30 minute perfusion of the stomach with $50 \%$ ethanol and after a 180 minute perfusion with saline after ethanol

\begin{tabular}{lclll}
\hline \multirow{5}{*}{ Time } & \multicolumn{2}{l}{ Injury grades } & & \\
\cline { 2 - 5 } & 0 & $I$ & $I I$ & $I I I$ \\
\hline Immediately after ethanol & $5 \cdot 8(2 \cdot 6)$ & $49 \cdot 2(4 \cdot 4)$ & $32 \cdot 2(5 \cdot 0)$ & $12 \cdot 8(3 \cdot 1)$ \\
180 minutes after ethanol & $18 \cdot 7(5 \cdot 4)^{\star}$ & $63 \cdot 1(8 \cdot 1)$ & $17 \cdot 1(3 \cdot 3)^{\star}$ & $1 \cdot 1(0 \cdot 7)^{\star \star}$ \\
\hline
\end{tabular}

Four grades of histological injury were recorded: 0 , no damage or damage affecting only the surface epithelial cells; I, shallow damage affecting up to $10 \%$ of the mucosal depth; II, medium damage affecting up to $25 \%$ of the mucosal depth; and III, deep damage involving $>25 \%$ of the mucosal depth affecting up to $25 \%$ of the mucosal depth; and III, deep damage involving $>25 \%$ of the mucosal depth.
The section length occupied by the respective injury grades was expressed as a percentage of the total The section length occupied by the respective injury grades was expressed as a percen
section length. Mean $(\mathrm{SEM}), \mathrm{n}=6 .{ }^{\star} \mathrm{p}<0 \cdot 05,{ }^{\star \star} \mathrm{p}<0 \cdot 01 \mathrm{v}$ immediately after ethanol.
The sections, which were taken randomly from the gastric corpus and included areas of haemorrhagical damage, were evaluated by an observer unaware of the treatment. For assessment of light microscopic injury, the sections were divided lengthwise into $10 \mu \mathrm{m}$ segments, and the grade of injury was determined for each segment. Four grades of histological injury were recorded: 0 , no damage or damage involving only the surface epithelial cells; I, shallow damage involving up to $10 \%$ of the mucosal depth; II, medium damage involving up to $25 \%$ of the mucosal depth; and III, deep damage involving $>25 \%$ of the mucosal depth. The section length occupied by the respective injury grades was expressed as a percentage of the total section length. ${ }^{610}$

\section{EXAMINATION OF GROSS INJURY}

Gross damage to the gastric glandular mucosa was assessed by computerised planimetry. The fixed stomachs were photographed, and the area of the glandular mucosa that was covered by visible haemorrhagical lesions was determined by the use of a digitising tablet and the software SigmaScan (Jandel Scientific, Corte Madera, CA, USA). Gross injury was evaluated by an observer unaware of the experimental treatment. The area covered by gross injury was expressed as a percentage of the area of the glandular mucosa of the rat stomach.

\section{EXPERIMENTAL PROTOCOLS}

Three sets of experiments were performed. Common to all experiments was that the stomachs were perfused with ethanol in saline for 30 minutes, after which the rats were divided into two groups. In one group, the stomachs were immediately excised, while in the other group the stomachs were perfused with saline for 180 minutes after the perfusion of ethanol, and unless stated, before they were processed for assessment of injury. As rapid repair (restitution) of injured gastric mucosa takes place only if the damage is non-haemorrhagical, ${ }^{15} 16$ the stomachs were exposed to concentrations of ethanol that caused haemorrhagical damage in less than $10 \%$ of the glandular mucosa. With this experimental design both rapid repair of nonhaemorrhagical lesions and any repair of haemorrhagical erosions could be studied.

In the first set of experiments, the stomachs of rats anaesthetised with urethane were perfused with $25 \%$ ethanol. ${ }^{910}$ In the second set of experiments, the stomachs of rats anaesthetised with phenobarbital were perfused with either $25 \%$ or $50 \%$ ethanol. The effect of gastric perfusion with $50 \%$ ethanol in vehicle and capsaicin pretreated rats anaesthetised with phenobarbital was studied in the third set of experiments.

\section{SUBSTANCES AND SOLUTIONS}

Aminophylline (Sigma, Deisenhofen, Germany), atropine (Merck, Darmstadt, Germany), and terbutaline (gift of Astra, Södertälje, Sweden) were dissolved in saline. Capsaicin (Serva, Heidelberg, Germany) was dissolved in absolute 
ethanol, followed by addition of Tween 80 and saline, ${ }^{6710}$ the final concentration being $12.5 \mathrm{mg} /$ $\mathrm{ml}$ capsaicin in $10 \%$ ethanol, $10 \%$ Tween 80 , and $80 \%$ saline ( $\mathrm{vol} / \mathrm{vol} / \mathrm{vol})$. The vehicle solution was prepared in the same manner. Phenobarbital sodium (Sigma, Deisenhofen, Germany) was dissolved in physiological saline $(33 \mathrm{mg} / \mathrm{ml}$ ), whereas urethane (Fluka, Buchs, Switzerland) was dissolved in water $(25 \%$, wt/wt)

\section{STATISTICS}

All data are presented as mean (SEM). Statistical evaluation of the results was performed by use of Student's $t$ test or one way analysis of variance followed by Duncan's test, where applicable. Probability values $\mathrm{p}<0.05$ were regarded as significant.

\section{Results}

INJURY AND RAPID REPAIR IN RATS

ANAESTHETISED WITH URETHANE

Perfusion of the stomach with $25 \%$ ethanol for 30 minutes led to the formation of grossly visible injury, which covered $8.6(1.9) \%(n=6)$ of the area of the glandular mucosa, as has been previously reported..$^{90}$ Scanning electron microscopy showed that intragastric ethanol caused a vast ablation of the surface epithelium, thus exposing the basal lamina (Fig 1A). Light microscopic assessment of the damage showed that, immediately after ethanol perfusion, about $25 \%$ of the sections displayed injury of grade 0 while about $60 \%$ of the sections was covered by superficial damage rated as injury grade I (Fig 2). Injury grades II and III were present in the remaining portions of the sections (Fig 2).

When, after the end of the 30 minute perfusion with ethanol $(25 \%)$, the stomachs were perfused again with saline for 180 minutes, the extent of damage at the light microscopic level did not change compared with the damage measured immediately after ethanol administration (Fig 2). Scanning electron microscopy, however, showed dynamic changes at the surface of the injured mucosa. In two rats whose stomachs were perfused with saline for 15 minutes after ethanol, many areas of the mucosa showed expulsion of damaged portions of the gastric glands (Fig 1B and C). Typically, the proximal but not distal part of the material extruding from the gastric pits was covered by a basement membrane (Fig 1C). Similar extrusions were seen in two rats whose stomachs were perfused with saline for 60 minutes after ethanol. Later (60-180 minutes) the basal lamina became exposed again and no sign of re-epithelialisation was noted 180 minutes after ethanol (Fig 1D). The lamina propria, however, became swollen so that the regular structure of the lamina propria was distorted (Fig 1D). Perfusion of the stomach with saline for four hours failed to cause any mucosal damage at the macroscopic and histological level $(n=4)$.

INJURY AND RAPID REPAIR IN RATS ANAESTHETISED WITH PHENOBARBITAL A 30 minute gastric perfusion with $25 \%$ ethanol failed to cause grossly visible lesions in six rats anaesthetised with phenobarbital, whereas a 30 minute exposure of the stomach to $50 \%$ ethanol resulted in formation of gross injury that covered $2 \cdot 0(0.6) \%(n=6)$ of the glandular mucosa. The Table shows the extent of histological injury, which compares the damage seen immediately after ethanol perfusion was stopped with the damage seen 180 minutes after ethanol. Histological damage was significantly reduced by 180 minutes after ethanol in rats given phenobarbital (Table) compared with rats anaesthetised with urethane (Fig 2). This was seen by a decrease of injury grades II and III and in an increase of injury grades 0 and I. Another experiment with eight rats showed appreciable repair of the gastric mucosa one hour after ethanol (data not shown), but the recovery was less pronounced than that seen three hours after ethanol.

\section{INJURY AND RAPID REPAIR IN VEHICLE AND} CAPSAICIN PRETREATED RATS ANAESTHETISED WITH PHENOBARBITAL

The gastric susceptibility to ethanol injury did not differ between vehicle pretreated and untreated rats anaesthetised with phenobarbital, as seen from a comparison of histological injury scores (Table and Fig 3). A 30 minute perfusion of $50 \%$ ethanol through the stomach of capsaicin pretreated rats, however, caused significantly more damage than in vehicle pretreated animals. In capsaicin pretreated rats, gross damage covered $12.0(2.7) \%(n=8)$ of the glandular mucosa, compared with $1 \cdot 2(0.5) \% \quad(n=9$, $\mathrm{p}<0.01)$ in vehicle pretreated rats. The severity of histological injury was also enhanced in capsaicin pretreated animals (Figs 3 and 4A). In vehicle pretreated rats only about $10 \%$ of the sections exhibited histological injury of grade III, whereas it was nearly $30 \%$ of the sections in capsaicin pretreated animals that was covered by this severe degree of damage (Figs 3 and 4A). Grade III injury occurred regularly in those areas of the mucosa that showed haemorrhagical damage at the macroscopic level. Scanning electron microscopy confirmed that ethanol caused a vast ablation of the surface epithelium, an effect that was particularly pronounced in capsaicin pretreated rats (Fig 5A and B). In certain areas of surface denudation, damaged cells and cell fragments were still visible inside the gastric pits, whereas in other areas no cells were discernible within the pits (Fig 5A).

When the stomachs were perfused with saline for a period of 180 minutes after ethanol, repair of the gastric mucosa was seen in both vehicle and capsaicin pretreated rats (Fig 3). The repair process resulted in a reduction of the severity of injury. As in the rats not pretreated with vehicle or capsaicin (Table), histological injury of grade III had almost disappeared and grade II injury was significantly reduced in vehicle pretreated animals 180 minutes after ethanol (Fig 3). The decrease in injury grades II and III was accompanied by an increase in grade I injury, whereas grade 0 injury did not significantly change in vehicle pretreated rats (Fig 3 ). Thus, there was still widespread damage in the superficial mucosa as seen at the light (Fig 4C) and scanning 

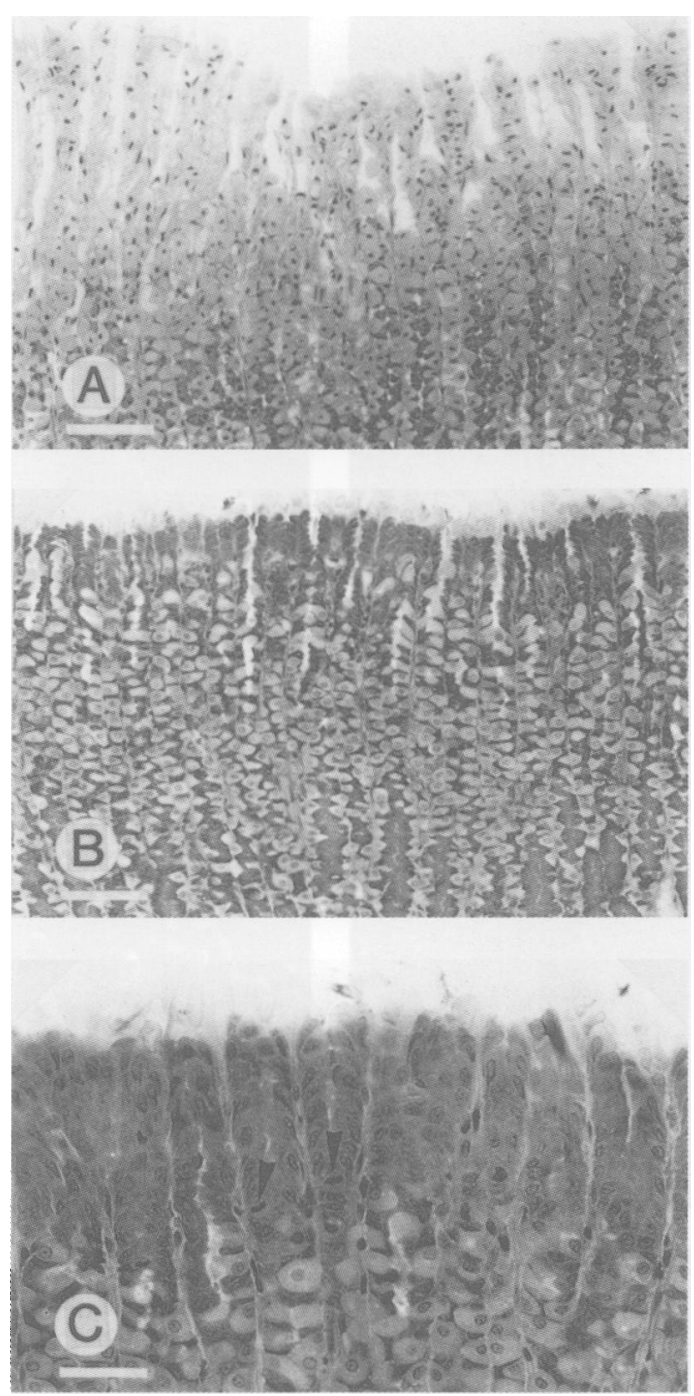

Figure 4: Light microscopic appearance of the gastric corpus mucosa of rats anaesthetised with phenobarbital subjected to a 30 minute perfusion of the stomach with $50 \%$ ethanol. The photomicrographs show sections that were taken immediately after ethanol perfusion $(A)$ or after 180 minutes of perfusion with saline after ethanol $(B, C) . A$ and $B$ are from capsaicin pretreated rats while $C$ is from a vehicle pretreated rat. Calibration bars: $200 \mu \mathrm{m}$ in $A$ and $B$, and $100 \mu \mathrm{m}$ in $C$. Arrowheads in $C$ point to mitosis.

electron (Fig 5E and F) microscopic level. The severity of the surface damage, however, was clearly diminished by 180 minutes after ethanol. Although the basal lamina remained visible at many places, the gastric pits of vehicle pretreated rats were uniformly filled with gastric glands (Figs 5E and F). A number of cells on the mucosal surface projected lamellipodia into the epithelial gaps (Fig 5F), while some neck cells had mitosis (Fig 4C).

The gastric mucosa of capsaicin pretreated rats showed a similar degree of repair to that of vehicle pretreated animals but, as the initial insult was more severe, recovery seen 180 minutes after ethanol had not proceeded to the same extent as that in vehicle pretreated rats (Fig 3 ). Thus, injury of grade III still covered about $10 \%$ of the sections, a percentage that was much higher than that measured in vehicle pretreated animals (Fig 3). When compared with the damage seen immediately after ethanol perfusion, however, injury grades II and III were reduced appreciably and injury grades 0 and I significantly increased in capsaicin pretreated rats (Fig 3). There was still widespread damage, however, to the superficial aspects of the mucosa (Fig 4B). The severity of damage ranged from small islets in which the surface remained completely denuded (Fig 5C) to areas in which the continuity of the surface epithelium was nearly complete (Fig 5D). As in vehicle pretreated animals, surface cells with lamellipodia and neck cells with mitosis were seen in capsaicin pretreated rats.

The content of calcitonin gene related peptide $(0.75(0.08) \mathrm{pmol} / \mathrm{g}, \mathrm{n}=5)$ in the gastric corpus wall of capsaicin pretreated rats was reduced by $90 \%$ compared with the gastric peptide content in vehicle pretreated animals (7.55 (0.84) $\mathrm{pmol} / \mathrm{g}, \mathrm{n}=5, \mathrm{p}<0.01)$

\section{Discussion}

The two main findings of this study are that (i) capsaicin sensitive afferent neurones do not seem to have an effect on rapid repair of injured gastric mucosa, although they contribute to the defence against injury, and (ii) anaesthetics can affect the recovery of gastric mucosa from damage. The second finding is important when ethical and legal considerations require the experiments to be conducted under anaesthesia, as was the case in this study. In an attempt to validate experimental conditions, when injury and rapid repair of the rat gastric mucosa can be studied under the influence of a longacting anaesthetic, we found that urethane anaesthesia prevents rapid repair of the ethanol damaged rat gastric mucosa within three hours after ethanol. After sloughing of the damaged cells from the surface of the mucosa, no sign of recovery or re-epithelialisation (restitution) was noted in urethane anaesthetised rats. It was beyond the scope of this study to enquire into the way by which urethane inhibits mucosal repair processes. This effect, however, may in some way be related to urethane's cytostatic action $^{26}$ and urethane's ability to augment synthesis and release of somatostatin and to reduce gastrin release and acid secretion in the rat stomach. ${ }^{27}$ Therefore, urethane anaesthesia is not suitable for the study of rapid repair of injured gastric mucosa but provides an experimental situation in which formation of gastric mucosal lesions can be examined without interference from rapid restitution processes.

When urethane was replaced by a longacting barbiturate anaesthetic, phenobarbital, progressing restitution and repair of the ethanol damaged gastric mucosa was seen one and three hours after ethanol. This finding is consistent with other reports showing that restitution of the damaged mucosa takes place in barbiturate anaesthetised rats. ${ }^{1328}$ Repair of the injured mucosa in phenobarbital anaesthetised rats was apparent from the increase in the depth of damage. Three hours after ethanol, injury had mostly receded to the superficial aspects of the mucosa, and the viability of cells in the neck region of the gastric glands was shown by the occurrence of mitotic divisions. Areas, in which deeper erosions persisted, were largely identical with those areas which exhibited haemorrhagical 

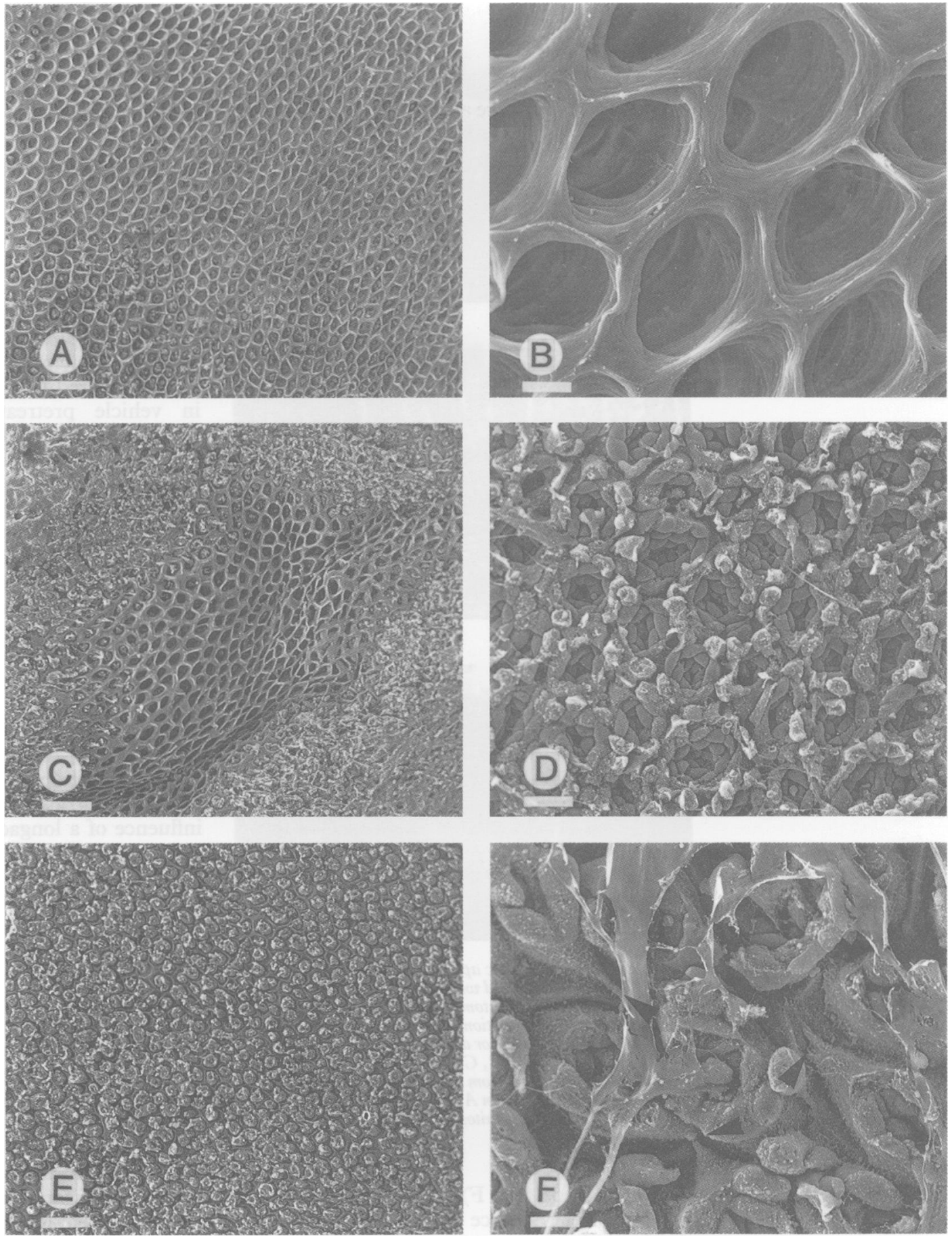

Figure 5: Scanning electron microscopical appearance of the gastric corpus mucosa of rats anaesthetised with phenobarbital subjected to a 30 minute perfusion of the stomach with $50 \%$ ethanol. The photomicrographs show the appearance of the mucosal surface immediately after ethanol perfusion $(A, B)$ or after 180 minutes of perfusion with saline after ethanol $(C-F) . A, B, C$, and $D$ are from capsaicin pretreated rats while $E$ and $F$ are from vehicle pretreated rats. Calibration bars in $A, C$, and $E$ : $100 \mu \mathrm{m}$, in D: $20 \mu \mathrm{m}$, in $B$ and $F: 10 \mu \mathrm{m}$. Arrowheads in F point to lamellipodia.

damage at the macroscopic level. In conscious rats restitution of non-haemorrhagical lesions proceeds so quickly that re-epithelialisation of the denuded surface is nearly complete within one hour. ${ }^{15} 16$ This process seems to be slowed down, however, in phenobarbital anaesthetised animals, although distinct features of restitution such as formation of lamellipodia in surface mucous cells and partial re-epithelialisation of the surface are evident three hours after ethanol. Slowing of restitution is also seen in in vitro conditions. ${ }^{142930}$

Ablation of capsaicin sensitive afferent neurones, as verified by a $90 \%$ depletion of their marker calcitonin gene related peptide ${ }^{23}$ from the gastric wall, resulted in a significant aggravation of ethanol injury. The finding that area and depth of haemorrhagical erosions was enhanced in capsaicin pretreated rats confirms previous findings at the macroscopic ${ }^{1-6}$ and histological ${ }^{+6}$ level. Sensory nerve ablation, however, did not impair rapid recovery from damage, as diminution of deep histological injury and re-epithelialisation of the denuded mucosal surface did not differ between vehicle and capsaicin pretreated rats. 
These data show, therefore, that the ability of the gastric mucosa to defend itself against noxious challenges depends on the integrity of its sensory innervation, whereas the rapid repair processes taking place after injury do not require an intact sensory innervation. Primary afferent neurones sensitive to the neurotoxic action of capsaicin have been characterised as neurones that are sensitive to chemical and other modalities of noxious stimuli. ${ }^{17}$ These nociceptive neurones seem to help an emergency function in the gastric mucosa as they monitor actual or potential harmful factors and signal for adequate measures of defence. ${ }^{621}$ Prominent among the protective mechanisms that are controlled by nociceptive neurones is the microcirculation of the gastric mucosa. This is because stimulation of capsaicin sensitive afferent neurones increases gastric mucosal blood flow ${ }^{1031}$ and ablation of these neurones prevents gastric hyperaemia in response to, for example, acid back diffusion. ${ }^{6}$ Whether other mechanisms of defence are also governed by capsaicin sensitive nociceptive neurones remains to be proved.

This work was supported by grant P7845-MED of the Austrian Scientific Research Council. The authors thank Dr Irmgard Th Lippe for her helpful comments on the manuscript and W Schluet for technical assistance.

1 Szolcsányi J, Barthó L. Impaired defense mechanism to peptic ulcer in the capsaicin-desensitized rat. In: Mózsik G, Hänninen O, Jávor T, eds. Gastrointestinal defense mechanisms. Oxford and Budapest: Pergamon and Akadémiai nisms. Oxford and

2 Holzer P, Sametz W. Gastric mucosal protection against ulcerogenic factors in the rat mediated by capsaicin-sensitive afferent neurones. Gastroenterology 1986; 91: 975-81.

3 Evangelista S, Maggi CA, Meli A. Evidence for a role of adrenals in the capsaicin-sensitive 'gastric defence mechanism' in rats. Proc Soc Exp Biol Med 1986; 182 568-9.

4 Esplugues JV, Whittle BJR. Morphine potentiation of ethanol-induced gastric mucosal damage in the rat. Role of local sensory afferent neurons. Gastroenterology 1990; 98: $82-9$.

5 Whittle BJR, Lopez-Belmonte J, Moncada S. Regulation of gastric mucosal integrity by endogenous nitric oxide: intergastric mucosal integrity by endogenous nitric oxide: interactions with prostanoids and sensory

6 Holzer P, Livingston EH, Guth PH. Sensory neurons signal for an increase in rat gastric mucosal blood flow in the face of pending acid injury. Gastroenterology 1991; 101: 416-23.

7 Holzer P, Lippe ITh. Stimulation of afferent nerve endings by intragastric capsaicin protects against ethanol-induced damage of gastric mucosa. Neuroscience 1988; 27: 981-7.

8 Holzer P, Pabst MA, Lippe ITh. Intragastric capsaicin protects against aspirin-induced lesion formation and bleeding in the rat gastric mucosa. Gastroenterology 1989; 96: 1425-33.
9 Holzer P, Pabst MA, Lippe ITh, Peskar BM, Peskar BA, Livingston EH, et al. Afferent nerve-mediated protection against deep mucosal damage in the rat stomach. Gastroenterology 1990; 98: 838-48.

10 Holzer P, Livingston EH, Saria A, Guth PH. Sensory neuron mediate protective vasodilatation in rat gastric mucosa. $A m \mathcal{F}$ mediate protective vasodilat

11 Takeuchi K, Niida H, Matsumoto J, Ueshima K, Okabe S. Gastric motility changes in capsaicin-induced cytoprotection in the rat stomach. $\mathcal{F}$ p $\mathcal{F}$ Pharmacol 1991; 55: 147-55.

12 Hollander D, Tarnawski AS. Gastric cytoprotection. New York: Plenum, 1990

13 Morris GP, Wallace JL. The roles of ethanol and of acid in the production of gastric mucosal erosions in rats. Virchows Arch [B] 1981; 38: 23-38.

14 Svanes K, Ito S, Takeuchi K, Silen W. Restitution of the surface epithelium of the in vitro frog gastric mucosa after damage with hyperosmolar sodium chloride. Morphologic and physiologic characteristics. Gastroenterology 1982; 82. 1409-26.

15 Lacy ER, Ito S. Rapid epithelial restitution of the rat gastric mucosa after ethanol injury. Lab Invest 1984; 51: 573-83.

16 Ito S, Lacy ER. Morphology of rat gastric mucosal damage, defense, and restitution in the presence of luminal ethanol. Gastroenterology 1985; 88: 250-60.

17 Holzer P. Capsaicin: cellular targets, mechanisms of action, and selectivity for thin sensory neurons. Pharmacol Rev 1991; 43: 143-201

18 Fujita $S$, Shimizu T, Izumi K, Fukuda T, Sameshima M Ohba N. Capsaicin-induced neuroparalytic keratitis-like corneal changes in the mouse. Exp Eye Res 1984; 38: 16575.

19 Kjartansson J, Dalsgaard C-J, Jonsson C-E. Decreased survival of experimental critical flaps in rats after sensory denervation with capsaicin. Plast Reconstr Surg 1987; 79: denerva

20 Maggi CA, Borsini F, Santicioli P, Geppetti P, Abelli L, Evangelista $\mathrm{S}$, et al. Cutaneous lesions in capsaicinpretreated rats. A trophic role of capsaicin-sensitive afferents? Naunyn Schmeidebergs Arch Pharmacol 1987; 336 $538-45$

21 Holzer $\mathbf{P}$. Local effector functions of capsaicin-sensitive sensory nerve endings: involvement of tachykinins, calcitonin gene-related peptide and other neuropeptides. Neuroscience 1988; 24: 739-68.

22 Maggi CA, Meli A. The sensory-efferent function of capsaicinsensitive sensory neurons. Gen Pharmacol 1988; 19: 1-43.

23 Green T, Dockray GJ. Characterization of the peptidergic afferent innervation of the stomach in the rat, mouse, and guinea-pig. Neuroscience 1988; 25: 181-93.

24 Varro A, Green T, Holmes S, Dockray GJ. Calcitonin generelated peptide in visceral afferent nerve fibres: quantitificaion by radioimmunoassay and determination of axonal tion by radioimmunoassay and determination

25 Holzer P, Peskar BM, Peskar BA, Amann R. Release of calcitonin gene-related peptide induced by capsaicin in the vascularly perfused rat stomach. Neurosci Lett 1990; 108: 195-200.

26 Guyer MF, Claus PE. Effects of urethane (ethyl carbamate) on mitosis. Proc Soc Exp Biol Med 1947; 64: 3-5.

27 Yang H, Wong H, Wu V, Walsh JH, Taché Y. Somatostatin monoclonal antibody immunoneutralization increases gastrin and gastric acid secretion in urethane-anesthetized rats. Gastroenterology 1990; 99: 659-65.

28 Wallace JL, Whittle BRJ. Role of mucus in the repair of gastric epithelial damage in the rat. Gastroenterology 1986; 91: 60311.

29 Rutten MJ, Ito S. Structural and functional changes by ethanol on in vitro guines pig gastric mucosa. Am $\mathcal{F}$ Physiol 1986 251: G518-28

30 Saario I, Rosen S, Carter K, Silen W. Effect of ethanol on frog gastric mucosa. Electrophysiologic and morphologic correlations. Gastroenterology 1988; 94: 638-46.

31 Lippe ITh, Pabst MA, Holzer P. Intragastric capsaicin enhances rat gastric acid elimination and mucosal blood flow by afferent nerve stimulation. BrF Pharmacol 1989; 96: 91100 . 